\title{
Second-line ramucirumab therapy for advanced hepatocellular carcinoma (REACH): an East Asian and non-East Asian subgroup analysis
}

\author{
Joon Oh Park ${ }^{1}$, Baek-Yeol Ryoo ${ }^{2}$, Chia-Jui Yen ${ }^{3}$, Masatoshi Kudo ${ }^{4}$, Ling Yang ${ }^{5}$, Paolo \\ B. Abada ${ }^{6}$, Rebecca Cheng7, Mauro Orlando ${ }^{8}$, Andrew X. Zhu' ${ }^{9}$, Takuji Okusaka ${ }^{10}$ \\ ${ }^{1}$ Samsung Medical Center, Sungkyunkwan University School of Medicine, Seoul, Republic of Korea \\ ${ }^{2}$ Asan Medical Center, University of Ulsan College of Medicine, Seoul, Republic of Korea \\ ${ }^{3}$ National Cheng Kung University Hospital, Tainan City, Taiwan \\ ${ }^{4}$ Kinki University School of Medicine, Osaka-Sayama City, Osaka, Japan \\ ${ }^{5}$ Eli Lilly and Company, Bridgewater, NJ, USA \\ ${ }^{6}$ Eli Lilly and Company, Indianapolis, IN, USA \\ ${ }^{7}$ Eli Lilly and Company, Taipei, Taiwan \\ ${ }^{8}$ Eli Lilly and Company, Buenos Aires, Argentina \\ ${ }^{9}$ Massachusetts General Hospital Cancer Center, Harvard Medical School, Boston, MA, USA \\ ${ }^{10}$ National Cancer Center Hospital, Tokyo, Japan
}

Correspondence to: Joon Oh Park, email: oncopark@skku.edu

Keywords: Asians, alpha-fetoprotein, clinical trial, liver neoplasms, vascular endothelial growth factor receptor-2

Received: May 23, $2016 \quad$ Accepted: October 10, $2016 \quad$ Published: October 20, 2016

\section{ABSTRACT}

Purpose: REACH investigated second-line ramucirumab therapy for advanced hepatocellular carcinoma.

Results: Median overall survival was 8.2 months for ramucirumab and 6.9 months for placebo (HR, 0.835; 95\% CI, 0.634-1.100; $p=0.2046)$ for East Asians, and 10.1 months for ramucirumab and 8.0 months for placebo (HR, 0.895; 95\% CI, 0.690-1.161; $p=0.4023$ ) for non-East Asians. Median overall survival in patients with baseline alpha-fetoprotein $\geq 400 \mathrm{ng} / \mathrm{mL}$ was 7.8 months for ramucirumab and 4.2 months for placebo (HR, 0.749; 95\% CI, 0.519-1.082; $p=0.1213$ ) for East Asians $(n=139)$, and 8.2 months for ramucirumab and 4.5 months for placebo (HR, $0.579 ; 95 \% \mathrm{CI}$, $0.371-0.904 ; p=0.0149)$ for non-East Asians $(n=111)$. The most common grade $\geq 3$ treatment-emergent adverse events in East Asians and non-East Asians included hypertension and malignant neoplasm progression.

Materials and methods: A post-hoc analysis of East Asians $(N=252)$ and nonEast Asians $(N=313)$ in the intent-to-treat population was performed.

Conclusions: In East Asians and non-East Asians, ramucirumab did not significantly prolong overall survival. In patients with baseline alpha-fetoprotein $\geq 400 \mathrm{ng} / \mathrm{mL}$, a potentially larger survival benefit was observed in both subgroups. Safety for East Asians was similar to non-East Asians.

\section{INTRODUCTION}

Among cancer deaths, liver cancer is the second most common cause [1]. Hepatocellular carcinoma represents approximately $70 \%$ to $90 \%$ of primary liver cancers $[1,2]$. The incidence rates of liver cancer are highest in East Asian (EA) countries [1]. Intermediate rates occur in Southern Europe and Northern America, and the lowest rates occur in Northern Europe [1]. In general, EA patients have a poorer prognosis than non-EA patients. In the Asia-Pacific study of sorafenib versus placebo in EA patients, median overall survival (OS) in both treatment arms was shorter than the median OS in either arm of the SHARP study of sorafenib versus placebo in a global 
cohort of patients $[3,4]$. Nonetheless, the relative hazard ratios for survival benefits were similar [3, 4]. Survival was also shorter for EA patients compared to non-EA patients in the GIDEON non-interventional study [5]. The reasons for the shorter survivals in EA patients remain unclear, but may include differences in tumor-related factors or patient characteristics. The most common cause of liver cancer in EA patients is hepatitis B virus infection, which is prevalent in this region, whereas hepatitis $\mathrm{C}$ virus or alcohol use are the most common causes of liver cancer in non-EA patients [6]. Disease management can also vary across regions [7], and EA patients are more likely to present at a more advanced stage of the disease $[8,9]$.

Vascular endothelial growth factor (VEGF) and VEGF receptor-2 (VEGFR-2)-mediated signaling are important in the proliferation of hepatocellular carcinoma tumors [10-13]. Ramucirumab, a recombinant human IgG1 monoclonal antibody, binds with high affinity and specificity to the extracellular domain of VEGFR-2, preventing angiogenesis via VEGF- and VEGFR-2mediated signaling [14]. Ramucirumab in patients with advanced hepatocellular carcinoma as a second-line treatment following first-line therapy with sorafenib did not demonstrate a significant OS improvement over best supportive care (primary endpoint) in the phase III REACH trial [15]. However, improvements in progression-free survival (PFS) and response rate were observed [15]. In a pre-specified subgroup analysis of patients with a baseline alpha-fetoprotein (AFP) $\geq 400 \mathrm{ng} / \mathrm{mL}$, ramucirumab treated patients had improved OS compared to placebotreated patients [15].

A post-hoc subgroup analysis of the REACH trial was performed in advanced hepatocellular carcinoma EA and non-EA patients following first-line therapy with sorafenib to explore safety and efficacy of ramucirumab treatment in these patient populations.

\section{RESULTS}

\section{Patients}

Figure 1 shows the CONSORT diagram for EA and non-EA patients. A total of 252 EA patients were randomized to receive ramucirumab $(N=126)$ or placebo $(N=126) ; 313$ non-EA patients were randomized to receive ramucirumab $(N=157)$ or placebo $(N=156)$.

Baseline patient and disease characteristics for EA and non-EA patients were generally well balanced between treatment arms (Table 1). Differences between EA and non-EA patients were observed for age, Eastern Cooperative Oncology Group performance status (ECOG PS), etiology of liver disease, primary tumor present, presence of extra-hepatic spread, Barcelona Clinic Liver Cancer stage, baseline AFP, prior systemic therapy, and reasons for discontinuation of prior sorafenib therapy. Most differences were consistent with EA patients having a worse prognosis compared to non-EA patients.

\section{Efficacy}

In EA patients, median OS for ramucirumabtreated patients was 8.2 months and 6.9 months for placebo-treated patients (stratified HR, 0.835; 95\% CI, 0.634-1.100; $p=0.2046$ ) (Figure 2). Median PFS was 2.2 months for the ramucirumab arm and 1.5 months for the placebo arm (stratified HR, 0.721; 95\% CI, 0.555-0.937; $p=0.0141$ ) (Figure 2). The objective response rate (ORR) was $5.6 \%(95 \% \mathrm{CI}, 2.7-11.0)$ for the ramucirumab arm and $0.8 \%(95 \% \mathrm{CI}, 0.1-4.4)$ for placebo $\operatorname{arm}(p=0.0298)$ (Table 2). The disease control rate (DCR) was $47.6 \%$ for the ramucirumab arm and $42.1 \%$ for the placebo arm $(p=0.3568)$.

In non-EA patients, median OS for ramucirumabtreated patients was 10.1 months and 8.0 months for placebo-treated patients (stratified HR, 0.895; 95\% CI, $0.690-1.161 ; p=0.4023$ ) (Figure 2). Median PFS was 4.5 months for the ramucirumab arm and 2.7 months for the placebo arm (stratified HR, 0.549; 95\% CI, 0.427-0.706; $p<0.0001)$ (Figure 2). The ORR was $8.3 \%(95 \% \mathrm{CI}$, 4.9-13.7) for the ramucirumab arm and $0.6 \%(95 \% \mathrm{CI}$, $0.1-3.5)$ for the placebo arm $(p=0.0012)$ (Table 2). The DCR was $63.1 \%$ for the ramucirumab arm and $48.7 \%$ for the placebo $\operatorname{arm}(p=0.0096)$ (Table 2).

In EA patients with AFP $\geq 400 \mathrm{ng} / \mathrm{mL}(n=139)$, median OS for the ramucirumab arm $(n=66)$ was 7.8 months and 4.2 months for the placebo arm $(n=73)$ (HR, 0.749; 95\% CI, 0.519-1.082; $p=0.1213$ ) (Figure 3). In non-EA patients with $\mathrm{AFP} \geq 400 \mathrm{ng} / \mathrm{mL}(n=111)$, median OS for ramucirumab-treated patients was 8.2 months $(n=53)$ and 4.5 months for placebotreated patients $(n=58)$ (stratified HR, $0.579 ; 95 \%$ CI, 0.371-0.904; $p=0.0149$ ) (Figure 3).

In EA patients with AFP $<400 \mathrm{ng} / \mathrm{mL}(n=113)$, median OS for the ramucirumab arm $(n=60)$ was 9.0 months and 12.4 months for the placebo arm $(n=53)$ (HR, 1.083; 95\% CI, 0.701-1.672; $p=0.7091$ ) (Figure 3). In non-EA patients with AFP $<400 \mathrm{ng} / \mathrm{mL}(n=197)$, median OS for ramucirumab-treated patients was 11.4 months $(n=100)$ and 11.6 months for placebotreated patients $(n=97)$ (stratified HR, $1.099 ; 95 \% \mathrm{CI}$, $0.783-1.543 ; p=0.5804$ ) (Figure 3 ).

Post-discontinuation systemic anti-cancer therapies (PDT) were similar for ramucirumab and placebo-treated patients in both EA and non-EA subgroups; however, a higher percentage of EA patients received PDT than non-EA patients (EA: $37.3 \%$ for the ramucirumab arm vs. $38.1 \%$ for the placebo arm; non-EA: $20.4 \%$ for the ramucirumab arm vs. $26.9 \%$ for the placebo arm).

\section{Safety}

The EA safety population consisted of 123 patients in the ramucirumab arm and 123 patients in the placebo arm. The non-EA safety population consisted of 154 patients in the ramucirumab arm and 153 patients in the 


\begin{tabular}{|c|c|c|c|c|}
\hline & \multicolumn{2}{|c|}{ East Asian } & \multicolumn{2}{|c|}{ Non-East Asian } \\
\hline & $\begin{array}{c}\text { Ramucirumab } \\
(N=126)\end{array}$ & $\begin{array}{l}\text { Placebo } \\
(N=126)\end{array}$ & $\begin{array}{c}\text { Ramucirumab } \\
(N=157)\end{array}$ & $\begin{array}{c}\text { Placebo } \\
(N=156)\end{array}$ \\
\hline \multicolumn{5}{|l|}{ Age, years } \\
\hline Median (range) & $61(34-85)$ & $59(25-83)$ & $66(28-87)$ & $64(30-85)$ \\
\hline$<65$ & $80(63.5)$ & $83(65.9)$ & $70(44.6)$ & $79(50.6)$ \\
\hline$\geq 65$ & $46(36.5)$ & $43(34.1)$ & $87(55.4)$ & $77(49.4)$ \\
\hline Male & $107(84.9)$ & $112(88.9)$ & $129(82.2)$ & $130(83.3)$ \\
\hline \multicolumn{5}{|l|}{ ECOG PS ${ }^{a}$} \\
\hline 0 & $63(50.0)$ & $63(50.0)$ & $96(61.1)$ & $90(57.7)$ \\
\hline 1 & $63(50.0)$ & $63(50.0)$ & $61(38.9)$ & $66(42.3)$ \\
\hline \multicolumn{5}{|l|}{ Etiology of liver disease } \\
\hline Hepatitis B & $79(62.7)$ & $76(60.3)$ & $30(19.1)$ & $31(19.9)$ \\
\hline Hepatitis C & $31(24.6)$ & $28(22.2)$ & $52(33.1)$ & $49(31.4)$ \\
\hline Significant alcohol use & $10(7.9)$ & $13(10.3)$ & $49(31.2)$ & $50(32.1)$ \\
\hline Steatohepatitis (fatty liver) & $3(2.4)$ & $4(3.2)$ & $16(10.2)$ & $16(10.3)$ \\
\hline Other & $3(2.4)$ & $3(2.4)$ & $3(1.9)$ & $7(4.5)$ \\
\hline Unknown & $10(7.9)$ & $8(6.3)$ & $30(19.1)$ & $26(16.7)$ \\
\hline Baseline Child-Pugh Class A & $125(99.2)$ & $125(99.2)$ & $152(96.8)$ & $151(96.8)$ \\
\hline Primary tumor present & $107(84.9)$ & $106(84.1)$ & $150(95.5)$ & $146(93.6)$ \\
\hline Macrovascular invasion present & $40(31.7)$ & $37(29.4)$ & $42(26.8)$ & $42(26.9)$ \\
\hline Extrahepatic spread present & $98(77.8)$ & $102(81.0)$ & $109(69.4)$ & $98(62.8)$ \\
\hline \multicolumn{5}{|l|}{ Baseline BCLC Stage } \\
\hline Stage B & $10(7.9)$ & $13(10.3)$ & $23(14.6)$ & $21(13.5)$ \\
\hline Stage C & $116(92.1)$ & $113(89.7)$ & $134(85.4)$ & $135(86.5)$ \\
\hline \multicolumn{5}{|l|}{ Prior sorafenib therapy } \\
\hline Sorafenib only & $99(78.6)$ & $102(81.0)$ & $145(92.4)$ & $151(96.8)$ \\
\hline Sorafenib and other systemic therapy & $27(21.4)$ & $24(19.0)$ & $12(7.6)$ & $5(3.2)$ \\
\hline \multicolumn{5}{|l|}{ Reason for discontinuation of sorafenib } \\
\hline Progressive disease & $116(92.1)$ & $112(88.9)$ & $130(82.8)$ & $127(81.4)$ \\
\hline Toxicity & $10(7.9)$ & $14(11.1)$ & $27(17.2)$ & $29(18.6)$ \\
\hline \multicolumn{5}{|l|}{ Alpha fetoprotein } \\
\hline$<400 \mathrm{ng} / \mathrm{mL}$ & $60(47.6)$ & $53(42.1)$ & $100(63.7)$ & $97(62.2)$ \\
\hline$\geq 400 \mathrm{ng} / \mathrm{mL}$ & $66(52.4)$ & $73(57.9)$ & $53(33.8)$ & $58(37.2)$ \\
\hline Missing & 0 & 0 & $4(2.5)$ & $1(0.6)$ \\
\hline
\end{tabular}

Data are n (\%) unless otherwise indicated. aPerformance status evaluated according to guidelines of the Eastern Cooperative Oncology Group (ECOG), with a performance status (PS) of 0 indicating asymptomatic, 1 restricted in strenuous activity but ambulatory and able to do light work, or 2 ambulatory and capable of all self-care but unable to work. Abbreviations: BCLC $=$ Barcelona Clinic Liver Cancer staging system; ECOG PS = Eastern Cooperative Oncology Group performance status .

placebo arm. The incidences of grade $\geq 3$ treatmentemergent adverse events (TEAEs) were higher in the ramucirumab arm than the placebo arm for EA and non-EA patients (Tables 3 and 4). Any grade TEAEs occurring in at least $15 \%$ of patients and at a higher rate (at least $10 \%$ difference) in the ramucirumab arm than the placebo arm were peripheral edema, diarrhea, headache, thrombocytopenia, proteinuria, hypertension, hypoalbuminemia, and epistaxis for EA patients (Table 3), and peripheral edema, ascites, asthenia, hypertension, headache, and thrombocytopenia for non-EA patients (Table 4). Grade $\geq 3$ TEAEs that occurred in at least 5\% 


\begin{tabular}{cccc}
\multicolumn{2}{c}{ East Asian } & \multicolumn{2}{c}{ Non-East Asian } \\
\hline Ramucirumab & Placebo & Ramucirumab & Placebo \\
$(N=126)$ & $(N=126)$ & $(N=157)$ & $(N=156)$ \\
\hline
\end{tabular}

Best overall response

Complete response

Partial response

Stable disease

Progressive disease

Not evaluable or assessed

Objective response rate

$$
\begin{aligned}
& 95 \% \mathrm{CI} \\
& p \text {-value }
\end{aligned}
$$

Disease control rate ${ }^{\mathrm{a}}$

$$
\text { 95\% CI }
$$

$p$-value

$\begin{array}{cc}0 & 0 \\ 7(5.6) & 1(0.8) \\ 53(42.1) & 52(41.3) \\ 57(45.2) & 62(49.2) \\ 9(7.1) & 11(8.7) \\ 7(5.6) & 1(0.8) \\ 2.7-11.0 & 0.1-4.4 \\ & 0.0298\end{array}$

$60(47.6)$

$39.1-56.3$
$53(42.1)$

$33.8-50.8$

$$
\begin{gathered}
1(0.6) \\
12(7.6) \\
86(54.8) \\
40(25.5) \\
18(11.5) \\
13(8.3) \\
4.9-13.7
\end{gathered}
$$

$0.1-3.5$

0.0012

$$
\begin{array}{ll}
99(63.1) & 76(48.7) \\
55.3-70.2 & 41.0-56.5
\end{array}
$$

Data are $n(\%)$ unless otherwise indicated. ${ }^{a}$ Denotes best response for complete response, partial response, or stable disease. Abbreviation: $\mathrm{CI}=$ confidence interval.

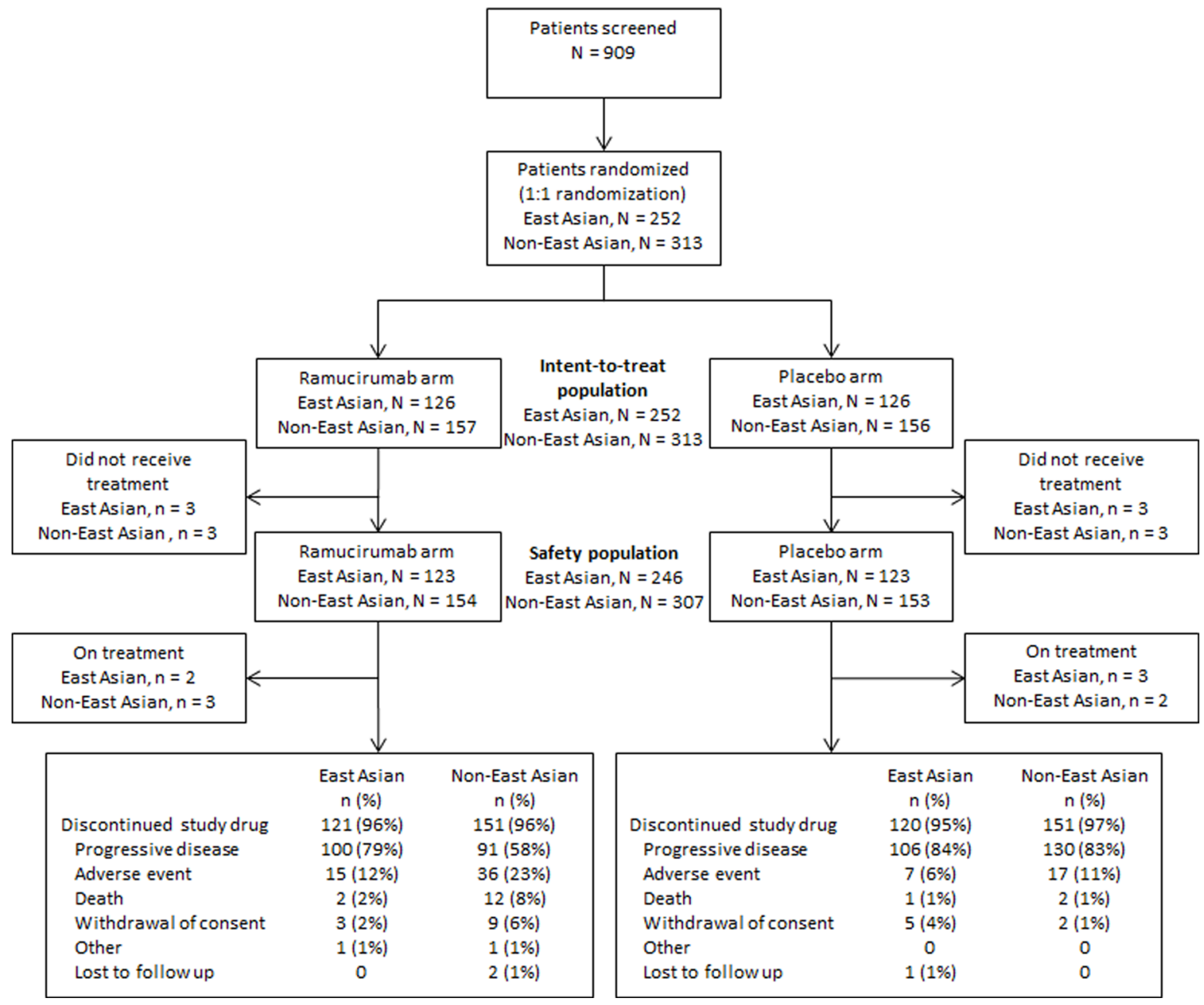

Figure 1: Trial profile for East Asian and non-East Asian patients. 


\begin{tabular}{|c|c|c|c|c|}
\hline & \multicolumn{4}{|c|}{ East Asian } \\
\hline & \multicolumn{2}{|c|}{$\begin{array}{l}\text { Ramucirumab } \\
\qquad(N=123)\end{array}$} & \multicolumn{2}{|c|}{$\begin{array}{c}\text { Placebo } \\
(N=123)\end{array}$} \\
\hline & Any Grade & Grade $\geq 3$ & Any Grade & Grade $\geq 3$ \\
\hline \multicolumn{5}{|l|}{ Treatment-emergent adverse events } \\
\hline Any & $119(96.7)$ & $64(52.0)$ & $110(89.4)$ & $48(39.0)$ \\
\hline Peripheral edema & $41(33.3)$ & 0 & $15(12.2)$ & 0 \\
\hline Fatigue & $28(22.8)$ & $2(1.6)$ & $20(16.3)$ & $4(3.3)$ \\
\hline Decreased appetite & $26(21.1)$ & $2(1.6)$ & $26(21.1)$ & 0 \\
\hline Diarrhea & $26(21.1)$ & 0 & $7(5.7)$ & 0 \\
\hline Headache & $25(20.3)$ & $1(0.8)$ & $3(2.4)$ & 0 \\
\hline Ascites & $24(19.5)$ & $4(3.3)$ & $14(11.4)$ & $4(3.3)$ \\
\hline Thrombocytopenia & $24(19.5)$ & $5(4.1)$ & $6(4.9)$ & 0 \\
\hline Proteinuria & $23(18.7)$ & $4(3.3)$ & $11(8.9)$ & 0 \\
\hline Pyrexia & $22(17.9)$ & 0 & $14(11.4)$ & 0 \\
\hline Hypertension & $21(17.1)$ & $8(6.5)$ & $8(6.5)$ & $1(0.8)$ \\
\hline Hypoalbuminemia & $19(15.4)$ & $2(1.6)$ & $6(4.9)$ & 0 \\
\hline AAT increase & $18(14.6)$ & $8(6.5)$ & $20(16.3)$ & $15(12.2)$ \\
\hline Epistaxis & $18(14.6)$ & 0 & $5(4.1)$ & 0 \\
\hline \multicolumn{5}{|l|}{ Adverse events of special interest } \\
\hline Liver injury/failure $^{a}$ & $59(48.0)$ & $23(18.7)$ & $38(30.9)$ & $24(19.5)$ \\
\hline Bleeding/hemorrhage ${ }^{a}$ & $38(30.9)$ & $6(4.9)$ & $17(13.8)$ & $8(6.5)$ \\
\hline Gastrointestinal hemorrhage ${ }^{b}$ & $10(8.1)$ & $4(3.3)$ & $7(5.7)$ & $5(4.1)$ \\
\hline Pulmonary hemorrhage ${ }^{b}$ & $4(3.3)$ & 0 & $2(1.6)$ & $1(0.8)$ \\
\hline Hepatic hemorrhage ${ }^{b}$ & $1(0.8)$ & $1(0.8)$ & $2(1.6)$ & $2(1.6)$ \\
\hline Proteinuria $^{a}$ & $24(19.5)$ & $4(3.3)$ & $11(8.9)$ & 0 \\
\hline Hypertension $^{\mathrm{a}}$ & $22(17.9)$ & $9(7.3)$ & $8(6.5)$ & $1(0.8)$ \\
\hline Renal failure $^{a}$ & $10(8.1)$ & $2(1.6)$ & $6(4.9)$ & 0 \\
\hline Infusion-related reaction ${ }^{\mathrm{a}}$ & $4(3.3)$ & 0 & $1(0.8)$ & 0 \\
\hline Arterial thromboembolic events ${ }^{\mathrm{a}}$ & $1(0.8)$ & 0 & $2(1.6)$ & $1(0.8)$ \\
\hline Venous thromboembolic events $\mathrm{a}$ & $1(0.8)$ & 0 & $1(0.8)$ & $1(0.8)$ \\
\hline
\end{tabular}

Data are $n(\%)$. Only treatment-emergent adverse events in $\geq 15 \%$ of patients in the ramucirumab arm in East Asian patients are reported. A patient was only counted once for each category. Missing grades are counted in 'Any Grade'. Adverse

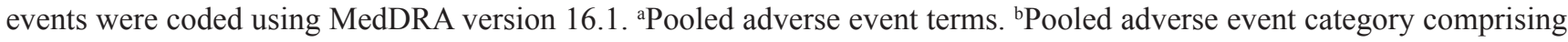
synonymous MedDRA preferred terms. Abbreviation: AAT = aspartate aminotransferase.

of patients and at a higher rate in the ramucirumab arm than the placebo arm were hypertension and malignant neoplasm progression for EA patients (Table 3; data not shown for malignant neoplasm progression), and hypertension, asthenia, ascites, general physical health deterioration, thrombocytopenia, and malignant neoplasm progression for non-EA patients (Table 4; data not shown for general physical health deterioration and malignant neoplasm progression).

The incidences of adverse events of special interest (AESIs) are shown in Tables 3 and 4 for EA and non-EA patients, respectively. Any grade AESIs that were more common (at least 10\% difference) in the ramucirumab arm than the placebo arm were liver injury/failure, bleeding/ hemorrhage, proteinuria, and hypertension for EA patients (Table 3), and liver injury/failure, hypertension, and proteinuria for non-EA patients (Table 4). Grade $\geq 3$ AESIs that occurred at a higher rate in the ramucirumab arm than the placebo arm were hypertension, proteinuria, and renal failure for EA patients (Table 3), and hypertension, renal failure, infusion-related reaction, and proteinuria for nonEA patients (Table 4). 


\begin{tabular}{|c|c|c|c|c|}
\hline & \multicolumn{4}{|c|}{ Non-East Asian } \\
\hline & \multicolumn{2}{|c|}{$\begin{array}{c}\text { Ramucirumab } \\
\quad(N=154)\end{array}$} & \multicolumn{2}{|c|}{$\begin{array}{c}\text { Placebo } \\
(N=153)\end{array}$} \\
\hline & Any Grade & Grade $\geq 3$ & Any Grade & Grade $\geq 3$ \\
\hline \multicolumn{5}{|l|}{ Treatment-emergent adverse events } \\
\hline Any & $151(98.1)$ & $108(70.1)$ & $150(98.0)$ & $84(54.9)$ \\
\hline Peripheral edema & $60(39.0)$ & $1(0.6)$ & $35(22.9)$ & $1(0.7)$ \\
\hline Ascites & $50(32.5)$ & $9(5.8)$ & $26(17.0)$ & $7(4.6)$ \\
\hline Asthenia & $48(31.2)$ & $13(8.4)$ & $33(21.6)$ & $4(2.6)$ \\
\hline Fatigue & $36(23.4)$ & $4(2.6)$ & $38(24.8)$ & $4(2.6)$ \\
\hline Nausea & $36(23.4)$ & 0 & $31(20.3)$ & 0 \\
\hline Decreased appetite & $35(22.7)$ & $3(1.9)$ & $24(15.7)$ & $2(1.3)$ \\
\hline Hypertension & $34(22.1)$ & $26(16.9)$ & $12(7.8)$ & $9(5.9)$ \\
\hline Abdominal pain & $32(20.8)$ & $4(2.6)$ & $42(27.5)$ & $10(6.5)$ \\
\hline Headache & $28(18.2)$ & $1(0.6)$ & $12(7.8)$ & 0 \\
\hline Cough & $27(17.5)$ & $1(0.6)$ & $14(9.2)$ & 0 \\
\hline Diarrhea & $25(16.2)$ & $3(1.9)$ & $31(20.3)$ & $1(0.7)$ \\
\hline Pyrexia & $24(15.6)$ & $1(0.6)$ & $12(7.8)$ & $1(0.7)$ \\
\hline Thrombocytopenia & $24(15.6)$ & $8(5.2)$ & $6(3.9)$ & $1(0.7)$ \\
\hline Constipation & $23(14.9)$ & 0 & $26(17.0)$ & 0 \\
\hline \multicolumn{5}{|l|}{ Adverse events of special interest } \\
\hline Liver injury/failure ${ }^{a}$ & $81(52.6)$ & $35(22.7)$ & $65(42.5)$ & $41(26.8)$ \\
\hline Bleeding/hemorrhage ${ }^{a}$ & $52(33.8)$ & $11(7.1)$ & $38(24.8)$ & $13(8.5)$ \\
\hline Gastrointestinal hemorrhage ${ }^{b}$ & $15(9.7)$ & $7(4.5)$ & $16(10.5)$ & $12(7.8)$ \\
\hline Pulmonary hemorrhage ${ }^{b}$ & $5(3.2)$ & $1(0.6)$ & $2(1.3)$ & $1(0.7)$ \\
\hline Hepatic hemorrhage $^{b}$ & $1(0.6)$ & $1(0.6)$ & 0 & 0 \\
\hline Hypertension $^{\mathrm{a}}$ & $34(22.1)$ & $26(16.9)$ & $12(7.8)$ & $9(5.9)$ \\
\hline Proteinuria $^{a}$ & $24(15.6)$ & $2(1.3)$ & $2(1.3)$ & 0 \\
\hline Infusion-related reaction ${ }^{\mathrm{a}}$ & $16(10.4)$ & $3(1.9)$ & $1(0.7)$ & 0 \\
\hline Renal failure $^{a}$ & $10(6.5)$ & $4(2.6)$ & $12(7.8)$ & $3(2.0)$ \\
\hline Venous thromboembolic events ${ }^{\mathrm{a}}$ & $5(3.3)$ & $2(1.3)$ & $3(2.0)$ & $3(2.0)$ \\
\hline Arterial thromboembolic events ${ }^{\mathrm{a}}$ & $1(0.6)$ & 0 & $2(1.3)$ & 0 \\
\hline Congestive heart failure $^{a}$ & 0 & 0 & $2(1.3)$ & $1(0.7)$ \\
\hline Healing complication ${ }^{a}$ & 0 & 0 & $1(0.7)$ & 0 \\
\hline
\end{tabular}

Data are $n(\%)$. Only treatment-emergent adverse events in $\geq 15 \%$ of patients in the ramucirumab arm in non-East Asian patients are reported. A patient was only counted once for each category. Missing grades are counted in 'Any Grade'. Adverse

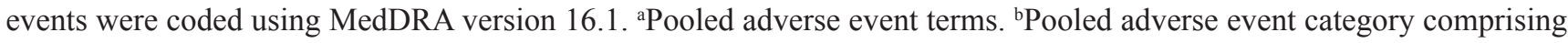
synonymous MedDRA preferred terms. Abbreviation: AAT = aspartate aminotransferase.

\section{DISCUSSION}

This subgroup analysis of REACH indicates that, while no significant OS benefit was shown in EA patients, there were improvements in PFS and ORR. Similar findings were noted in non-EA patients. Patients with AFP $\geq 400 \mathrm{ng} / \mathrm{mL}$ appeared to have a more favorable OS benefit in both the EA and non-EA groups, consistent with the findings in the overall intent-to-treat (ITT) population with $\mathrm{AFP} \geq 400 \mathrm{ng} / \mathrm{mL}$.

Overall, the survival benefit of ramucirumab was comparable in EA patients and non-EA patients, although EA patients had a shorter median OS compared with non-EA patients. A shorter median OS for EA patients versus non-EA patients was also observed in the SHARP and Asia-Pacific studies of sorafenib in hepatocellular 
carcinoma $[3,4]$. The shorter median OS for EA patients in REACH may partly be due to a higher prevalence of baseline characteristics associated with poor prognosis in EA patients compared to non-EA patients. For instance, EA patients in REACH had a higher incidence of hepatitis $\mathrm{B}$ infection, macrovascular invasion, extrahepatic spread, Barcelona Clinic Liver Cancer stage C, increased concentration of AFP, and poorer ECOG PS than non-EA patients. In addition, more EA patients were aged less than 65 years compared with non-EA patients. Notably, patients in the Asia-Pacific study were also reported to have a higher incidence of hepatitis B, extrahepatic spread, Barcelona Clinic Liver Cancer stage C, poorer ECOG PS, and younger age compared to patients enrolled in the SHARP study $[3,4]$. Post-discontinuation systemic anticancer therapy in REACH is unlikely to have contributed to the shorter OS in EA patients compared with non-EA patients given that a higher percentage of EA patients $(38 \%)$ received PDT compared with non-EA patients (24\%). Furthermore, no treatment has demonstrated a survival benefit to date in hepatocellular carcinoma after sorafenib treatment [15-18]. The improvement in PFS in EA patients was consistent with the improvement in non-
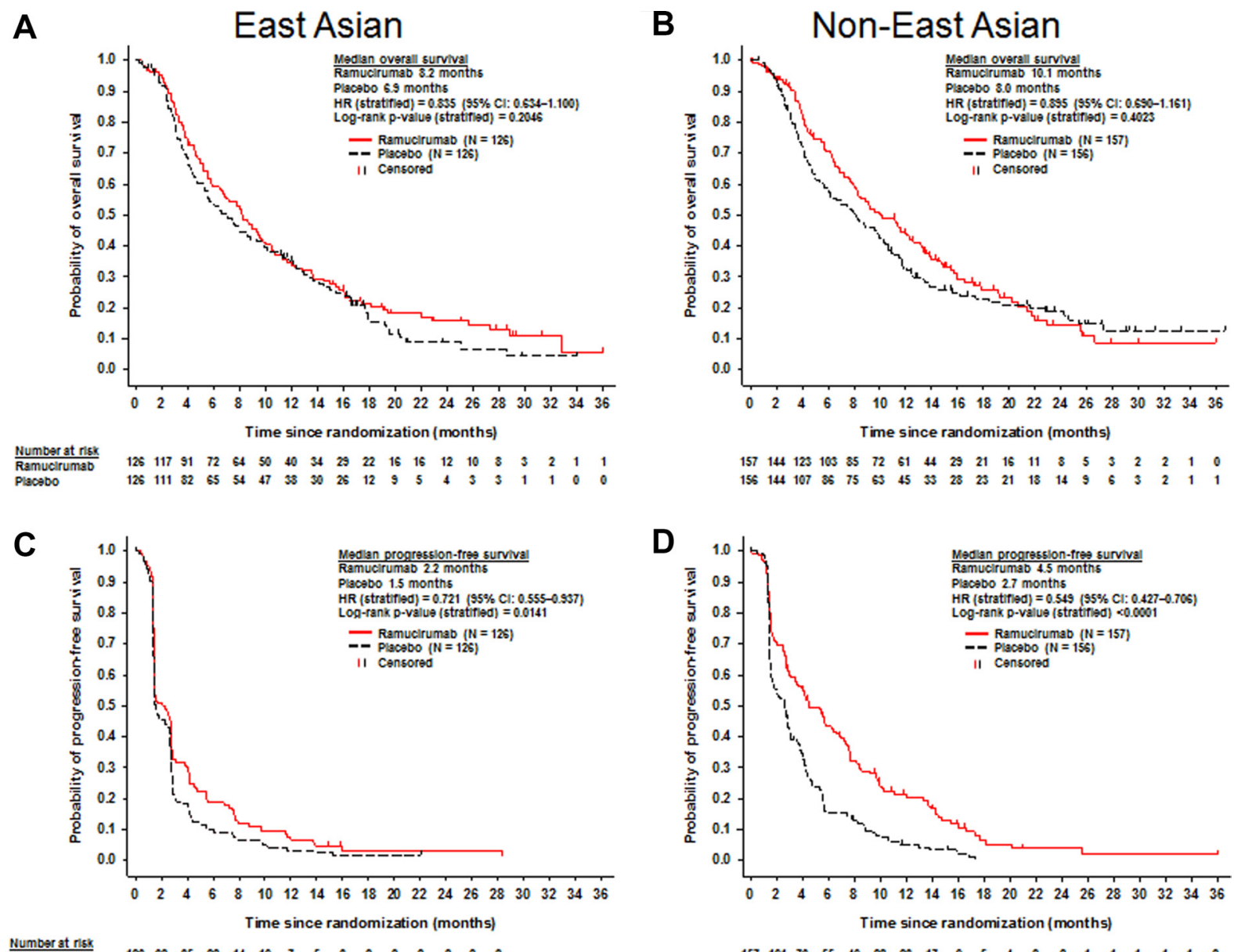

Figure 2: Kaplan-Meier plots of overall survival (A and B) and progression-free survival (C and D) for East Asian (A and C) and non-East Asian patients (B and D).

EA patients, although PFS was shorter and the DCR was lower for EA patients than non-EA patients. The shorter PFS and DCR for EA patients may reflect the poorer prognosis and more rapidly progressive disease in the EA population. Despite known regional differences in the etiology and prognosis of hepatocellular carcinoma, ramucirumab demonstrated comparable survival efficacy in both EA and non-EA patients. These efficacy findings were similar to the overall REACH ITT population [15].

In patients with a baseline AFP $\geq 400 \mathrm{ng} / \mathrm{mL}$, an improvement in OS was observed in both EA and non-EA patients treated with ramucirumab compared to placebo. This did not reach significance in the EA subgroup, likely due to the limitations of small sample size. Nonetheless, the difference in median OS was similar in the EA and non-EA subgroups and is generally consistent with the survival benefit observed in the overall ITT population with a baseline AFP $\geq 400 \mathrm{ng} / \mathrm{mL}$ in REACH [15]. This benefit was observed despite the overall poorer prognosis associated with EA patients compared to non-EA patients. We note that in the patients with baseline AFP $\geq 400 \mathrm{ng} / \mathrm{mL}$, both EA and non-EA patients share a similar median OS in the placebo arm, which suggests that selection of

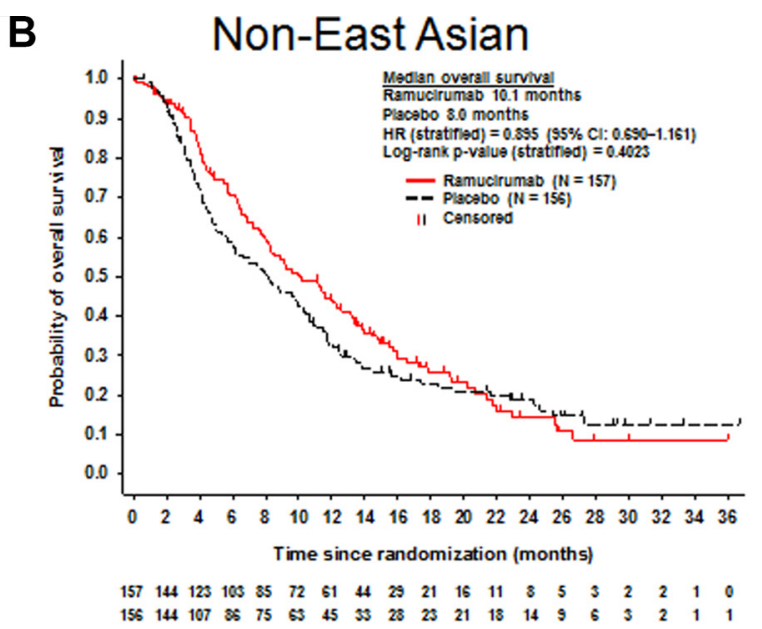


this subset of patients may normalize any differences in prognosis between regions. Consistent with the overall ITT population with baseline AFP $<400 \mathrm{ng} / \mathrm{mL}$ [15], no OS benefit was observed in EA or non-EA patients with ramucirumab treatment. The OS results from these subgroup analyses demonstrate that a baseline AFP $\geq 400 \mathrm{ng} / \mathrm{mL}$ may identify patients who are most likely to benefit from ramucirumab treatment, regardless of whether they are from EA or non-EA regions.

The efficacy benefits for EA and non-EA patients were achieved with an acceptable safety profile. The majority of AESIs were grade $1-2$, and the grade $\geq 3$ AESIs were generally comparable between EA and nonEA patients. The observed safety profiles for EA and non-EA patients were consistent with the underlying disease state and the overall ITT populations in trials of ramucirumab $[15,19,20]$. Liver injury and bleeding are of particular concern in patients with advanced hepatocellular carcinoma, who often have underlying cirrhosis. In both EA and non-EA patients, increases in the low grade AESIs of liver injury/failure and bleeding/hemorrhage were observed in the ramucirumab arms compared with the placebo arms, but an increase in higher grade events
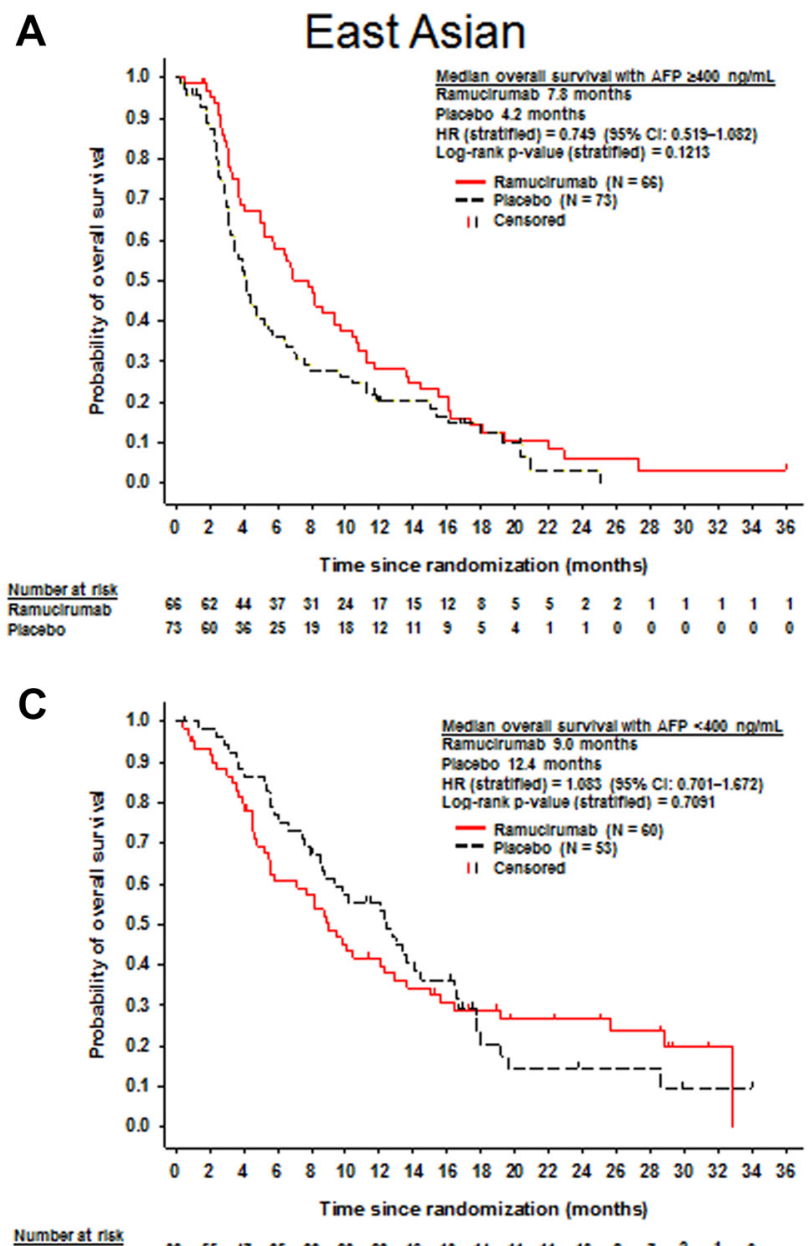

Figure 3: Kaplan-Meier plots of overall survival in patients with baseline alpha-fetoprotein $\geq 400 \mathrm{ng} / \mathrm{mL}$ (A and B) and alpha-fetoprotein $<400 \mathrm{ng} / \mathrm{mL}$ (C and D) for East Asian (A and C) and non-East Asian patients (B and D).

was not observed. Notably, no increased rate of high grade AESIs was observed in EA patients compared to nonEA patients, despite the prevalence of poor prognostic characteristics in the EA subgroup that might have put these patients at higher risk with ramucirumab treatment.

This subgroup analysis has a number of limitations including the fact that the study was not designed or powered to show significance in the EA and non-EA subgroups, which makes it difficult to make accurate inferences. Furthermore, this analysis was post-hoc and caution should be used when interpreting the results. Despite these limitations, the efficacy observations in the subgroups defined by an AFP $<$ or $\geq 400 \mathrm{ng} / \mathrm{mL}$ have been very consistent, and therefore seem unlikely to be due to chance.

In this subgroup analysis of the REACH trial, ramucirumab generally demonstrated consistent efficacy across EA and non-EA regions. The data indicate that patients with baseline AFP $\geq 400 \mathrm{ng} / \mathrm{mL}$ may be deriving the majority of the benefit observed in both EA and non-EA patients. Ramucirumab was well tolerated in both EA and non-EA patients. Further evaluation of ramucirumab in patients with advanced hepatocellular
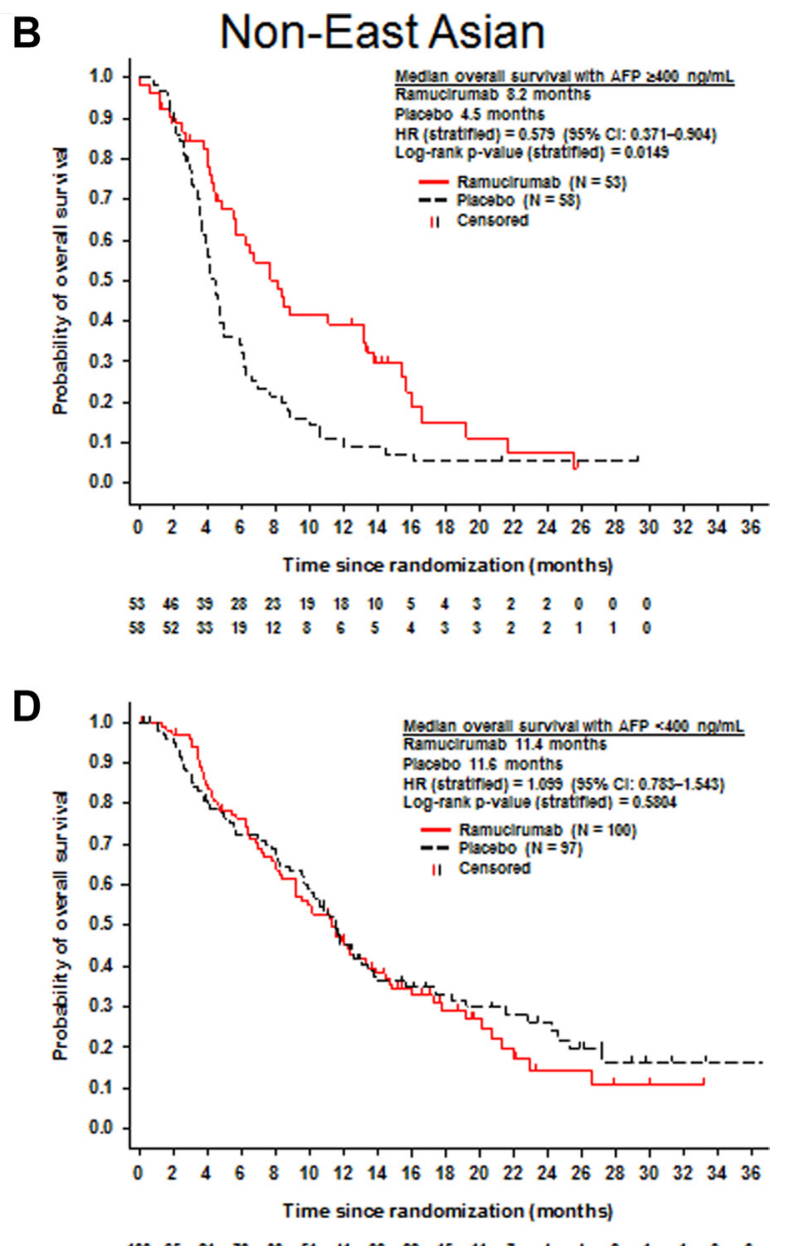
carcinoma is warranted. The REACH-2 trial will evaluate the efficacy and safety of ramucirumab in a global cohort of participants with hepatocellular carcinoma and elevated baseline AFP (ClinicalTrials.gov Identifier: NCT02435433).

\section{MATERIALS AND METHODS}

\section{Study design and patients}

The study design and demographic information for patients in REACH have been published previously [15]. Each center's institutional review board or independent ethics committee approved this study. The study followed the guiding principles of the Declaration of Helsinki and the Good Clinical Practice Guidelines of the International Conference on Harmonization. All patients provided written informed consent before enrollment. This study is registered with ClinicalTrials.gov, number NCT01140347.

\section{Randomization and procedures}

Randomization and procedures have been published previously [15]. Patients were randomly assigned in a 1:1 ratio to receive either ramucirumab $8 \mathrm{mg} / \mathrm{kg}$ or placebo intravenously every two weeks until disease progression, unacceptable toxicity, or withdrawal of consent. All patients received best supportive care. Predefined dose modifications were allowed to manage treatment-related toxicity. Randomization was stratified by geographic region (region $1[n=65]$ : Brazil, Canada, and the United States vs. region $2[n=248]$ : Australia, Europe, and Israel vs. region $3[n=252]$ : East Asia) and etiology of liver disease (hepatitis B vs. hepatitis C vs. other etiologies). Region 1 consisted of Brazil $(n=27)$, Canada $(n=1)$, and the United States $(n=37)$; region 2 consisted of Australia $(n=11)$, Austria $(n=8)$, Belgium $(n=8)$, Bulgaria $(n=6)$, the Czech Republic $(n=20)$, Finland $(n=3)$, France $(n=59)$, Germany $(n=40)$, Hungary $(n=1)$, Israel $(n=2)$, Italy $(n=51)$, the Netherlands $(n=3)$, Norway $(n=2)$, Portugal $(n=2)$, Romania $(n=7)$, Spain $(n=21)$, Sweden $(n=2)$, and Switzerland $(n=2)$; and region 3 consisted of Hong Kong $(n=24)$, Japan $(n=93)$, Philippines $(n=1)$, South Korea $(n=70)$, Taiwan $(n=58)$, and Thailand $(n=6)$.

\section{Statistical analysis}

Statistical methodology was the same as published previously [15]. The EA and non-EA subgroups were separately analyzed. The EA patient population was defined and analyzed as patients enrolled at study sites in region 3. The non-EA patient population was defined and analyzed as patients enrolled at study sites in regions 1 and 2 combined.

\section{ACKNOWLEDGMENTS}

We thank the patients, their families, the study sites, and the study personnel who participated in this clinical trial. This study was sponsored by Eli Lilly and Company. Medical writing support was provided by Marissa Philpott and Andrew Sakko, and editorial support was provided by Noelle Gasco, of inVentiv Health Clinical and funded by Eli Lilly and Company.

\section{CONFLICTS OF INTEREST}

Paolo B. Abada, Rebecca Cheng, Mauro Orlando, and Ling Yang are employees of Eli Lilly and Company. Andrew X. Zhu has acted in a consulting or advisory role for Amgen, Exelixis, and Sanofi, received research funding from Bayer and Onyx Pharmaceutical, and received grants from Eli Lilly and Company during the conduct of the study. All remaining authors have declared no conflicts of interest.

\section{FINANCIAL SUPPORT}

This study was sponsored by Eli Lilly and Company.

\section{Authors' contributions}

Paolo B. Abada, Rebecca Cheng, Mauro Orlando, and Ling Yang conceived and designed the study. Masatoshi Kudo, Takuji Okusaka, Joon Oh Park, BaekYeol Ryoo, Chia-Jui Yen, and Andrew X. Zhu collected the data. All authors analyzed and interpreted the data. All authors were involved in the drafting, review, and approval of the manuscript and the decision to submit for publication.

\section{REFERENCES}

1. Ferlay J, Soerjomataram I, Ervik M, Dikshit R, Eser S, Mathers C, Rebelo M, Parkin DM, Forman D, Bray F. GLOBOCAN 2012 v1.0, Cancer Incidence and Mortality Worldwide: IARC CancerBase No. 11. Lyon, France: International Agency for Research on Cancer; 2013 [cited 2016 Feb 12]. Available from: http://globocan.iarc.fr.

2. Torre LA, Bray F, Siegel RL, Ferlay J, Lortet-Tieulent J, Jemal A. Global cancer statistics, 2012. CA Cancer J Clin. 2015; 65:87-108.

3. Cheng AL, Kang YK, Chen Z, Tsao CJ, Qin S, Kim JS, Luo R, Feng J, Ye S, Yang TS, Xu J, Sun Y, Liang H, et al. Efficacy and safety of sorafenib in patients in the AsiaPacific region with advanced hepatocellular carcinoma: a phase III randomised, double-blind, placebo-controlled trial. Lancet Oncol. 2009; 10:25-34. 
4. Llovet JM, Ricci S, Mazzaferro V, Hilgard P, Gane E, Blanc JF, de Oliveira AC, Santoro A, Raoul JL, Forner A, Schwartz M, Porta C, Zeuzem S, et al. SHARP Investigators Study Group. Sorafenib in advanced hepatocellular carcinoma. N Engl J Med. 2008; 359:378-390.

5. Kudo M, Lencioni R, Ye SL, Bronowicki JP, Chen XP, Dagher L, Furuse J, Geschwind JF, Ladrón de Guevara L, Papandreou C, Sanyal AJ, Takayama T, Yoon SK, et al. Regional differences in treatment history, practices, and outcomes: final analysis of Gideon (Global Investigation of Therapeutic Decisions in Hepatocellular Carcinoma and of its Treatment with Sorafenib). Seventh International Liver Cancer Association Annual Conference, Washington, D.C., September 13-15, 2013 Final Programme \& Book of Abstracts, pgs 11-12 [abstract O-011]. Available from: http:/www.ilca2013.org/be-bruga/ilca2013/files/ ILCAProvisionalProgramme2013_Final.pdf. Cited 2016 February 12.

6. El-Serag HB. Hepatocellular carcinoma. N Engl J Med. 2011; 365:1118-1127.

7. Fong ZV, Tanabe KK. The clinical management of hepatocellular carcinoma in the United States, Europe, and Asia: a comprehensive and evidence-based comparison and review. Cancer. 2014; 120:2824-2838.

8. Llovet JM. Updated treatment approach to hepatocellular carcinoma. J Gastroenterol. 2005; 40:225-235.

9. Llovet JM, Burroughs A, Bruix J. Hepatocellular carcinoma. Lancet. 2003; 362:1907-1917.

10. Sullivan LA, Brekken RA. The VEGF family in cancer and antibody-based strategies for their inhibition. MAbs. 2010; 2:165-175.

11. Tugues S, Koch S, Gualandi L, Li X, Claesson-Welsh L. Vascular endothelial growth factors and receptors: antiangiogenic therapy in the treatment of cancer. Mol Aspects Med. 2011; 32:88-111.

12. Amini A, Masoumi MS, Morris DL, Pourgholami MH. The critical role of vascular endothelial growth factor in tumor angiogenesis. Curr Cancer Drug Targets. 2012; 12:23-43.

13. Zhu AX, Duda DG, Sahani DV, Jain RK. HCC and angiogenesis: possible targets and future directions. Nat Rev Clin Oncol. 2011; 8:292-301.

14. Spratlin JL, Cohen RB, Eadens M, Gore L, Camidge DR, Diab S, Leong S, O'Bryant C, Chow LQ, Serkova NJ, Meropol NJ, Lewis NL, Chiorean EG, et al. Phase I pharmacologic and biologic study of ramucirumab
(IMC-1121B), a fully human immunoglobulin G1 monoclonal antibody targeting the vascular endothelial growth factor receptor-2. J Clin Oncol. 2010; 28:780-787.

15. Zhu AX, Park JO, Ryoo BY, Yen CJ, Poon R, Pastorelli D, Blanc JF, Chung HC, Baron AD, Pfiffer TE, Okusaka T, Kubackova K, Trojan J, et al. REACH Trial Investigators. Ramucirumab versus placebo as second-line treatment in patients with advanced hepatocellular carcinoma following first-line therapy with sorafenib (REACH): a randomised, double-blind, multicentre, phase 3 trial. Lancet Oncol. 2015; 16:859-870.

16. Llovet JM, Decaens T, Raoul JL, Boucher E, Kudo M, Chang C, Kang YK, Assenat E, Lim HY, Boige V, Mathurin P, Fartoux L, Lin DY, et al. Brivanib in patients with advanced hepatocellular carcinoma who were intolerant to sorafenib or for whom sorafenib failed: results from the randomized phase III BRISK-PS study. J Clin Oncol. 2013; 31:3509-3516.

17. Johnson PJ, Qin S, Park JW, Poon RT, Raoul JL, Philip PA, Hsu CH, Hu TH, Heo J, Xu J, Lu L, Chao Y, Boucher E, et al. Brivanib versus sorafenib as first-line therapy in patients with unresectable, advanced hepatocellular carcinoma: results from the randomized phase III BRISKFL study. J Clin Oncol. 2013; 31:3517-3524.

18. Zhu AX, Kudo M, Assenat E, Cattan S, Kang YK, Lim HY, Poon RT, Blanc JF, Vogel A, Chen CL, Dorval E, PeckRadosavljevic M, Santoro A, et al. Effect of everolimus on survival in advanced hepatocellular carcinoma after failure of sorafenib: the EVOLVE-1 randomized clinical trial. JAMA. 2014; 312:57-67.

19. Fuchs CS, Tomasek J, Yong CJ, Dumitru F, Passalacqua R, Goswami C, Safran H, dos Santos LV, Aprile G, Ferry DR, Melichar B, Tehfe M, Topuzov E, et al. REGARD Trial Investigators. Ramucirumab monotherapy for previously treated advanced gastric or gastro-oesophageal junction adenocarcinoma (REGARD): an international, randomised, multicentre, placebo-controlled, phase 3 trial. Lancet. 2014; 383:31-39.

20. Wilke H, Muro K, Van Cutsem E, Oh SC, Bodoky G, Shimada Y, Hironaka S, Sugimoto N, Lipatov O, Kim TY, Cunningham D, Rougier P, Komatsu Y, et al. RAINBOW Study Group. Ramucirumab plus paclitaxel versus placebo plus paclitaxel in patients with previously treated advanced gastric or gastro-oesophageal junction adenocarcinoma (RAINBOW): a double-blind, randomised phase 3 trial. Lancet Oncol. 2014; 15:1224-1235. 